\title{
Latency dependence of word-initial letter integration by the saccadic system
}

\author{
KARINE DORÉ and CÉCILE BEAUVILLAIN \\ Université René Descartes, Paris, France
}

\begin{abstract}
Two experiments are reported in which saccadic eye movements were examined when the eyes moved to words in which the properties of the word-initial letters differed. It was found that the effect of saccade latency on landing position depended on the properties of the word-initial letters. Under short saccade latencies, landing positions deviated toward the word beginning in the presence of orthographically irregular/informative beginning (OI/IB) letters. This result is interpreted as an influence of the orthographic encoding process that has detected an unusual letter grouping. With longer saccade latencies, an increase of the saccade size was observed for OI/IB words, whereas orthographically regular/uninformative beginning words did not show the effect. It is suggested that this may be a consequence of the dynamics of parafoveal word information processing.
\end{abstract}

There has been considerable interest in the understanding of saccade programming during reading. Understanding saccadic performance in reading is vitally important for modeling the relation between the processes associated with the integration of linguistic information and those responsible for eye movements in reading. Recently, the discussion has focused on the properties of the parafoveal words that influence the position where the eyes land.

Considerable data have shown that fixation locations within words are strongly influenced by the length of the word in parafoveal vision (O'Regan, 1979; Rayner, 1979) and that perturbing word-boundary information has a major effect on eye movement patterns (Morris, Rayner, \& Pollatsek, 1990; Pollatsek \& Rayner, 1982). Readers fixate systematically left of the center of a word. This phenomenon, labeled the "preferred viewing location" by Rayner (1979), may be explained by the notion that the center of gravity calculation is not done on the word as it appears in the visual field, but on the cortical representation of this configuration. The fact that central vision is better represented in the cortex than peripheral information may have the consequence that in the center of gravity calculation, greater weight is given to elements of the configuration that are closer to the center of the field. This would explain a deviation of first fixation position to the left of the geometric center of the configuration (Coëffé \& O'Regan, 1987; Vitu, 1991; see also Deubel, Wolf, \& Hauske, 1984; Findlay, 1982).

Although most of the data indicate that word boundary information plays a crucial part in directing where the eyes go next, there is evidence that saccade length is influenced

This research is based in part on a thesis submitted by K.D. at the Université René Descartes. The authors would like to thank two anonymous reviewers for their helpful suggestions and comments on an earlier draft of this manuscript. Correspondence should be addressed to K. Doré, Laboratoire de Psychologie Expérimentale, 28 rue Serpente, Paris 75006 France (e-mail: beauvi@idf.ext.jussieu.fr). by more than word boundary information. Recently, Beauvillain, Doré, and Baudouin (1996) have shown that the orthographic properties of the word-initial letters influenced the initial placement of the eyes within a word. An orthographically irregular and informative letter sequence at the word beginning led to a deviation of the landing positions toward the word beginning. This effect of orthographically irregular letters was also seen when varying the relative intensity of the word-initial and ending letters. Although the eye usually tends to land in a position that can be described as the center of gravity of the configuration, the effect of luminance distribution is strongly attenuated when the word-initial letters are orthographically irregular. Thus, the weight of a word-initial letter sequence at the word beginning should be a function of its orthographic regularity. This suggests that the critical information integrated by the saccadic system is sublexical and is related to the orthographic encoding process that operates on the word-initial letters. Consistent with this view, Hyönä (1995) showed in a sentence-reading situation that an irregular letter cluster at the beginning of a word attracts the eye toward the word beginning.

However, a mechanism directing the eyes to a position in a word that is a function of the lexical information obtained parafoveally would have to predict longer saccades toward orthographically irregular than toward orthographically regular word beginnings because the initial letters of irregular words are informative and effective for activating lexical representations. For example, because of acuity limitations, initial letters in the word might be identified during the fixation prior to going to the word (Rayner, McConkie, \& Zola, 1980). Furthermore, with greater identification of the first part of the word, the eye could be sent farther into informative-beginning words. A mechanism of saccade programming that is a function of the information extracted from the parafoveal word has been proposed in order to explain the fact that in a text-reading situation, saccades to a parafoveal word 
are slightly larger when the letters of the parafoveal word are available than when they are masked by a matched string of Xs or random letters (Inhoff, 1989; Inhoff \& Rayner, 1986; Rayner, Well, Pollatsek, \& Bertera, 1982). In addition, words can occasionally be identified without direct fixation; when they are, the duration of the fixation prior to skipping the word is inflated (Hogaboam, 1983; Pollatsek, Rayner, \& Balota, 1986). Following Morrison (1984), word skipping occurs when the parafoveal word is identified before the programming of a saccade to it. In Balota, Pollatsek, and Rayner's study (1985), parafoveal words were skipped more often when prior contextual constraints were high than when they were low, presumably because parafoveal word identification was more successful when constraints were high. A mechanism that is a function of lexical information obtained parafoveally should have predicted longer saccades toward orthographically irregular word beginnings because their initial letters are more informative.

One way of understanding how word-initial letter information can influence landing positions in words might be to manipulate the timing of the available information. Experiments by Morris et al. (1990) varied the availability of word boundary and letter information in a textreading situation by making available word boundary and letter information at various points in the fixation of the preceding word. Parafoveal information was either available from the onset of fixation within the word $n-1$, or the mask was removed 50,150 , or $250 \mathrm{msec}$ after the onset of the fixation within the word $n-1$. The data show that both the presence of the letters of the upcoming words and the spaces that mark beginning and end of these words influenced how far the eyes moved. Moreover, the timing of presentation of these two types of information was a crucial factor in determining where the reader fixated next. Having letter information causes the eyes to move farther into the word if this information is available early in a fixation, but by $150 \mathrm{msec}$, landing position is determined on the basis of boundary information alone. This suggests that although word length information exerts strong effects on saccade size because it is integrated quickly by the saccadic computation system, letter information from the parafoveal word may also affect saccade computation if it is available with sufficient strength early in a fixation. These findings reinforce the claim that parafoveal letter information may influence saccade length. Additionally, the source of word information that is integrated from the parafovea by the saccadic computation system may crucially depend on the timing of the available information. However, previous results do not elucidate which source of letter information is integrated at different times of the parafoveal processing that affects landing positions in words.

To examine the role of word-initial letter information in saccade programming as a function of the timing of parafoveally available information, we propose controlling the delay of saccade triggering to isolated target words. Experiments using saccade delaying in the saccade to a target letter within a string of letters have shown an im- provement of saccade accuracy when the moment of saccade triggering is sufficiently delayed (Coëffé \& O'Regan, 1987). In the case of saccades to words where there is no specific target, it is important to test how the metrics of saccades to words change as a function of the time given to the letter and word identification process. We might suppose that if the saccade is triggered early, saccadic computation system would be interrupted before the lexical information derived from the beginning letters has been activated. Consequently, only the first stages of the word identification process would influence the landing positions. Thus, the orthographic encoding of the word that is initiated in parafovea may allow the detection of orthographically irregular letters at the word beginning, and this would be a salient signal for the saccade. If this were the explanation for the previously observed orthographic effect, it should be possible to diminish the attraction toward the orthographically irregular word-initial letters by allowing more time for the word identification process to progress. Moreover, it should be possible to determine whether or not saccades may be influenced by the lexical information derived from the beginning letters when more time is given to the saccadic computation system. If this is the case, longer saccades should be observed when the word-initial letters are orthographically irregular since their informative value is high. Indeed, the size of the set of the potential word candidates is much more limited when the word-initial letters are orthographically irregular rather than when they are regular.

In the present paper, we reexamined the effects of wordinitial letter information on landing position in words. We controlled the delay of saccade triggering to words so that it was possible to investigate the effects of the wordinitial letters on a large range of saccade latency. Saccade latency was manipulated by requiring participants to remain fixated on the central fixation mark until it disappeared. Two imposed saccade latencies were used. In the 0 -msec condition, there was no imposed delay for the saccade triggering, whereas in the 150 -msec imposed delay, the word was presented during $150 \mathrm{msec}$ in the parafovea before a saccade was allowed onto the word. As in the Beauvillain et al. (1996) experiments, two types of words were selected according to the orthographic regularity and the informativeness of the three initial letters. Orthographically irregular/informative beginning (OI/IB) words began with three initial letters that were not shared by another word and were composed of two initial bigrams that were very infrequent at this position. For instance, the French word cymbale shares its initial trigram cym with no other word, and the mean frequency of use of the two initial bigrams $c y$ and $y m$ is very low. Orthographically regular/uninformative beginning (OR/UB) words began with three initial letters that were shared by many words and were composed of frequent initial bigrams. For instance, the French word poussin shares its initial trigram pou with many words ( pouvoir, poussin, poudrer, poulain, pourpre ...) and the mean frequency of use of the two initial bigrams po and ou is very high. In the task used, the reader had first to fixate a position before mov- 
ing his or her eye to read a target word and then to saccade to a sequence of three asterisks that were replaced by a second word when the eyes had left the target word. Next, the target word disappeared and subjects had to perform a semantic judgment task on another relatedunrelated word. Our reading task eliminated influences such as the effect of the processing of the current word on the acquisition of parafoveal word information (Henderson \& Ferreira, 1990) by studying saccades in an isolated word that was preceded and followed by stimuli that did not involve linguistic processing. Moreover, this experimental procedure allowed us to keep constant the eccentricity of the target word since the initial landing positions in words depend on the point from which the eye is launched (McConkie, Kerr, Reddix, \& Zola, 1988).

\section{EXPERIMENT 1}

\section{Method}

Subjects. Eighteen students from our laboratory participated in the experiment. All of them had previously participated in eye movement experiments and were native French speakers with normal uncorrected vision.

Apparatus. In the experiment, the subject's eyes were $70 \mathrm{~cm}$ from a Hewlett-Packard 1310A CRT (P-15 phosphor) with the characteristic that removing a character resulted in a drop to $10 \%$ of brightness within $.003 \mathrm{msec}$. Text characters were controlled by a Graphic Translator that was interfaced with an AT486 computer. One character space equaled $45^{\prime}$ of visual angle. Words were presented in uppercase letters.

Eye movement recording was accomplished with a Bouis Oculometer System. The eye tracker had a resolution of $6^{\prime}$ of arc, and output was linear over $12^{\circ}$ of visual angle. The signal from the oculometer was sampled every $2 \mathrm{msec}$. Details about the eye movement recording apparatus, calibration procedure, and numerical data processing can be found in Beauvillain and Beauvillain (1995).

Procedure. The subjects were tested individually. Head stability was obtained by a submaxillar dental print and a forehead rest. A calibration of the eye-tracking system began each session. In order to test the accuracy of the eye movement recording, each trial was preceded and followed by a fixation bar displayed at $6^{\circ}$ left and at $6^{\circ}$ right of the center of vision. The sequence of events during one trial was as follows: (1) Subjects were instructed to look at the fixation bar displayed at $6^{\circ}$ left of the center of vision. (2) When the computer detected an accurate fixation on the left fixation bar, the target word was displayed at 3 character spaces to its right. Simultaneously, three asterisks were displayed 1.5 character spaces to the right of the target word. Subjects were required to remain fixated on the fixation bar until a cross appeared on the fixation bar. This was the signal to move the eye to the stimulus. If the computer detected a saccade before the presentation of the cross, the trial was discarded. (3) Only when a cross was displayed on the fixation bar were subjects allowed to move their eyes to the stimulus. In the 0 msec delay condition, the cross was displayed at the same time as the target word. In the 150-msec delay condition, the cross was displayed $150 \mathrm{msec}$ after the onset of the target word. (4) When the eyes crossed an invisible boundary located 1.5 character spaces after the end of the target word, the target word disappeared and the three asterisks were replaced by a comparison word. (5) Subjects were asked to judge whether the comparison word was semantically related to the target word. The comparison word had either an obvious semantic relation to the target word or no relation. No speed instructions were given to the subject for this task. (6) The subjects responded by pressing one of two buttons. (7) A fixation bar was displayed at $6^{\circ}$ to the right of the center of vision. Then the next trial began. The experimental block of trials was preceded by 30 training trials that had the same characteristics. Subjects responded correctly $99 \%$ of the time. The number of errors did not show any effect of delay and type of word conditions.

Materials. Twenty-two seven-letter French words were used in the experiment (see the Appendix). These words were selected according to two criteria: the degree of informativeness and the orthographic regularity of the three word-initial letters. First, informativeness was indexed by the number of seven-letter words listed in the Trésor de la Langue Française (1971) that began with the same trigram as the target word. The mean frequency of the initial trigram of OI/IB words calculated over the 7,417 French seven-letter words was 1.00 , indicating that no other word shared their initial trigram. The mean frequency of initial trigram of OR/UB words was 32.25 , indicating that a large set of candidates shared their initial trigrams. Moreover, the degree of orthographic regularity of the informative and uninformative letter sequence at the word beginning was controlled so that the OI/IB words were composed of two lowpositional-frequency bigrams whereas the uninformative part of the OR/UB words was composed of two high-positional-frequency bigrams. The mean positional frequencies of the six bigrams that formed OI/IB words were, respectively, 38, 22, 31, 63, 102, and 364 , whereas those of OR/UB words were $160,190,61,75,85$, and 362. The members of each word type were matched on printed word frequency (Trésor de la Langue Française, 1971). The mean frequency calculated on a corpus of 38 million words was 428 for the OI/IB words and 408 for OR/UB words.

Because the number of pixels influenced the luminance of letters, the luminance was measured for the set of uppercase letters with a photometer specially designed for a low-luminance screen resolution (resolution of $10^{-5} \mathrm{~cd} / \mathrm{m}^{2}$ ) with an absolute precision of $\pm 15 \%$ in white light. Care was chosen to select words in which the center of gravity of the luminance was very near the geometric center of the word (4.50, at the middle of the fourth letter of a seven-letter word). The mean center of gravity of the stimuli used was $4.74(S D=$ $0.42)$ for $\mathrm{OI} / \mathrm{IB}$ words and $4.75(S D=0.31)$ for OR/UB words.

Design. The design was a $2 \times 2$ factorial design in which the two imposed delays and the two types of word were within-subject factors. Each subject was exposed to the two delay conditions but no subject saw the same target word more than once. Two sets of stimuli were constructed in such a way that each word was presented under two latency conditions across the two sets. Subjects were randomly assigned to one of the two sets. The two delay conditions were mixed within the experimental session.

Data analysis. Trials were eliminated in which blinks occurred $(1.9 \%)$ or when the eye position measurement was not precise enough $(3.6 \%)$. Consistent with many prior studies, only data in which saccade latency lasted more than $50 \mathrm{msec}$ were analyzed. The proportions of such anticipatory saccades were $3 \%$. If a saccade was detected before the presentation of the signal to move the eye, the trial was discarded. Very few errors of this type were observed (less than $2 \%$ ) after practice. Altogether, $10.5 \%$ of the trials were excluded from the analyses reported below.

\section{Results and Discussion}

Landing positions. Table 1 gives the mean landing positions as a function of word type and imposed delay conditions. Analyses of variance were conducted in which both subjects $\left(F_{1}\right)$ and items $\left(F_{2}\right)$ were treated as random effects. Overall, the mean landing positions were not affected by type of word. There was a significant effect of the imposed delay in saccade triggering $\left[F_{1}(1,17)=\right.$ $\left.9.25, p<.01 ; F_{2}(1,70)=8.02, p<.01\right]$. This effect indicates that the eye landed farther into the word for the 150 msec than for the 0 -msec delay condition. A significant interaction between the type of word and the delay in 
Table 1

Mean Landing Positions and Saccade Latencies (in Milliseconds) as a Function of Imposed Delay and Type of Word in Experiment 1

\begin{tabular}{lccccc}
\hline & \multicolumn{3}{c}{ Imposed Delay } \\
\cline { 2 - 3 } \cline { 5 - 6 } Type of & \multicolumn{2}{c}{$0 \mathrm{msec}$} & & \multicolumn{2}{c}{$150 \mathrm{msec}$} \\
\cline { 2 - 3 } \cline { 5 - 6 } Word & Landing & Saccade & & Landing & Saccade \\
\hline OI/IB & 3.34 & 314 & & 3.70 & 258 \\
OR/UB & 3.57 & 328 & & 3.52 & 269 \\
\hline
\end{tabular}

Note-Ol/IB, orthographically irregular/informative beginning; OR/UB, orthographically irregular/uninformative beginning.

saccade triggering occurred $\left[F_{1}(1,17)=20.84, p<.0005\right.$; $\left.F_{2}(1,70)=7.30, p<.01\right]$. This interaction shows that for OI/IB words, the eyes land farther into the word in the 150-msec imposed delay than in the 0-msec imposed delay $\left[F_{1}(1,17)=49.85, p<.0001 ; F_{2}(1,35)=14.9, p<\right.$ $.0005]$, whereas no effect of the imposed delay was observed for OR/UB words $\left(F_{1}\right.$ and $\left.F_{2}<1\right)$. Interestingly, the data show that the effect of word type on landing position depends on the imposed delay in saccade triggering. Indeed, for the $0-\mathrm{msec}$ delay condition, the eyes landed less far in the OI/IB words than in the OR/UB words $\left[F_{1}(1,17)=11.16, p<.005 ; F_{2}(1,70)=5.16, p<.025\right]$, whereas for the 150 -msec delay condition, the eyes landed farther in the OI/IB words than in the OR/UB words $\left[F_{1}(1,17)=5.61, p<.05 ; F_{2}(1,70)=6.01, p<.025\right]$.

A closer examination of the landing position distributions as a function of the type of word for each delay condition is given in Figure 1. It can be seen that the landing position distributions are almost Gaussian in shape. The pattern of landing positions is quite similar to those observed in research studying eye movements during text or isolated word reading (McConkie et al., 1988; Rayner, 1979), in which the eyes generally land between the beginning and the middle of words. These landing position distributions reveal constant differences that support analyses on mean landing position. As can be seen in Figure 1A, which represents the distributions obtained with the 0 -msec imposed delay condition, the eye deviated slightly more toward the word beginning for OI/IB than for OR/UB words, with a difference of 0.5 character spaces between the modes of the distributions. With the 150-msec delay condition (Figure 1B), an opposite difference of 0.5 character spaces can be observed between the modes of the two distributions. Quantitatively, the amplitude of these effects is greater than the noise level of the eye-tracking system ( $\pm 6^{\prime}$ of arc; Beauvillain $\&$ Beauvillain, 1995). Thus, the obtained parameters for the mean can be accepted as characterizing the distributions and can be used to test hypotheses about change in the tendency of the whole landing position distributions as a function of the variables being investigated.

Saccade latencies. Saccade latencies are shown in Table 1. It can be seen that latencies of the saccades were affected by the delay condition. These latencies were longer in the 0 -msec delay condition than in the $150-\mathrm{msec}$ delay condition $\left[F_{1}(1,17)=67.6, p<.0005 ; F_{2}(1,70)=\right.$ $91.0, p<.0005]$. There was no effect of word type $\left[F_{1}(1,15)=1.71 ; F_{2}(1,70)=2.88, p<.10\right]$, nor a significant interaction with the delay condition $\left[F_{1}(1,17)=\right.$ $\left.1.52 ; F_{2}<1\right]$. Figure 2 presents the distributions of saccade latencies. The distributions did not center on the same modal values for the two delay conditions. It can be clearly seen that, for the two word types, the saccade latencies were globally longer in the 0 -msec delay condition than they were in the 150-msec delay condition.

Because saccade latency was not independent of the delay condition, we cannot determine whether the effect observed on landing positions was not caused by abnormal saccade latency effects. Moreover, it can be seen in Table 1 that the mean observed saccade latencies were higher than the usual mean value of the saccadic reaction time (RT) to a target $(200 \mathrm{msec})$. This does not allow us to determine whether the observed effects on landing positions depended exclusively on the imposed delay. The increasing of latency may have been due to the mixing of delay conditions within the same experimental session. Indeed, saccade latency has been shown to be lengthened by $100 \mathrm{msec}$ when the moment of the occurrence of the saccade triggering signal is varied rather than constant (Michard, Têtard, \& Lévy-Schoen, 1974). Moreover, experiments in which different temporal conditions were mixed reported that saccade latency was longer when no delay was imposed than when the signal to move the eye was delayed (Cohen \& Ross, 1977, 1978; Findlay, 1981b; Rayner, Slowiaczek, Clifton, \& Bertera, 1983; L. E. Ross \& S. M. Ross, 1980; S. M. Ross \& L. E. Ross, 1981). Temporal uncertainty seems to have been responsible for this increased saccade latency. Indeed, saccade latency was not affected by imposed delay when the presentation of the different delay conditions was done in separate experimental blocks (Coëffé \& O'Regan, 1987).

The present experiment suggests that when the moment of saccade triggering is delayed, the saccade amplitude results in the eye falling at a position farther into the word. Interestingly, this effect occurs only for OI/IB words. Without delay in saccade triggering, the presence of orthographically irregular letters at the word beginning determines a deviation of landing position toward the word beginning, replicating findings from an earlier study (Beauvillain et al., 1996) showing that such word-initial letters lead the eye to land farther into the word when the saccade latency is delayed. The most straightforward explanation for these effects appears to be that different levels of information are involved in the processing of the word characteristics. It is assumed that the difference in landing positions for the two types of words is the result of the orthographic encoding process that allows the instantaneous discrimination of salient initial-letter groupings, whereas the increase in saccade amplitude when the saccade triggering is delayed is likely the result of lexical activation processes. Because the initial letters of ortho- 

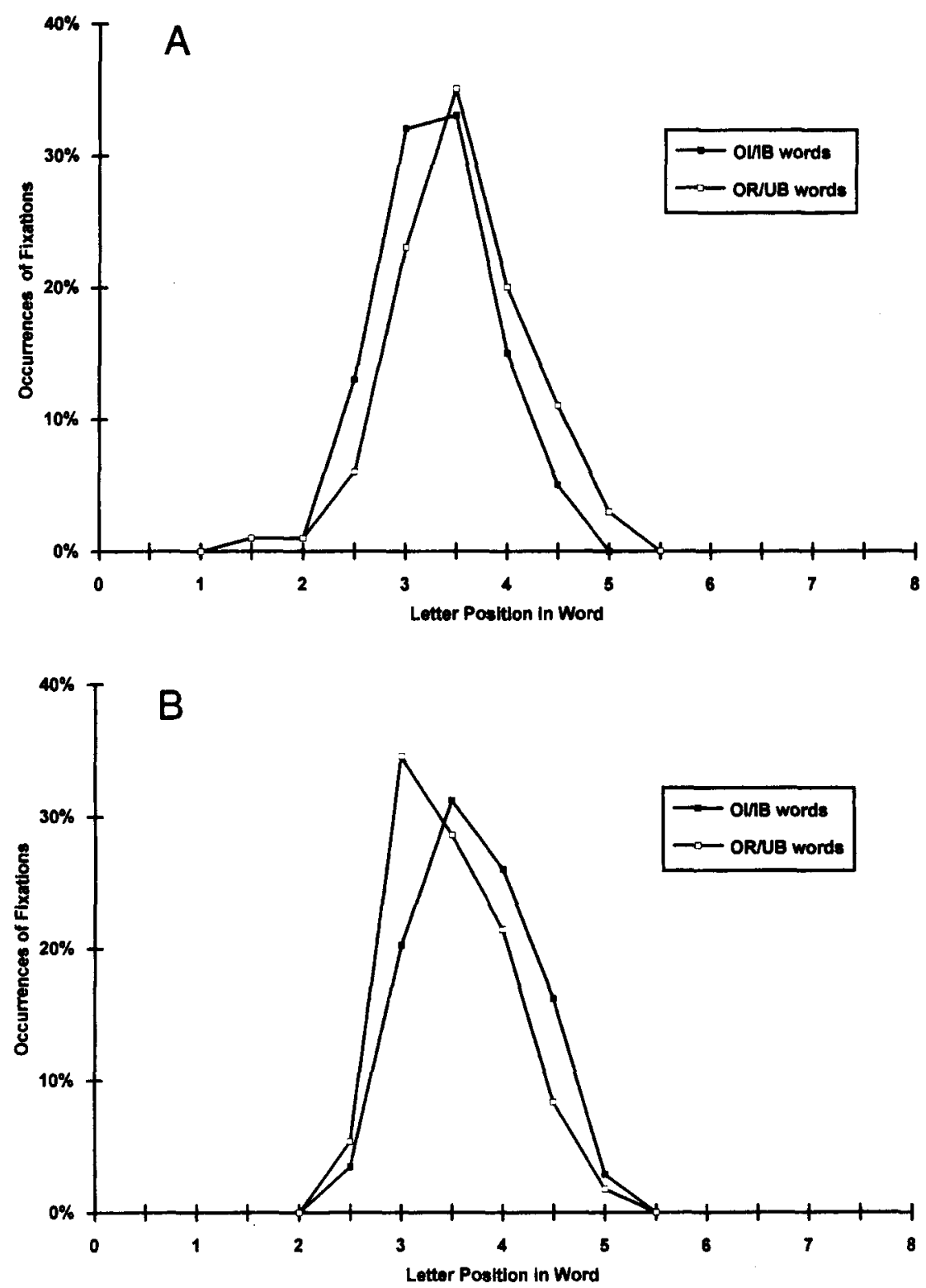

Figure 1. Landing position distributions of primary saccades in Experiment 1 as a function of the word type for the (A) 0-msec imposed delay and the (B) 150-msec imposed delay. Each bin represents a 0.5 character-space range. Letter positions 0 and 8 are the spaces to the left and to the right of the word, respectively. OI/LB, orthographically irregular/informative beginning; $\mathrm{OR} / \mathrm{UB}$, orthographically regular/uninformative beginning.

graphically irregular and informative-beginning words are more effective in activating a lexical representation, there is an effect on saccade amplitude. However, the present method of manipulating delay within the same experimental session was not totally successful, because delay conditions affected observed saccade latencies. The following experiment examined again how landing positions for the two types of words relate to saccade latency when temporal uncertainty of saccade triggering is reduced (the two delay conditions are presented in separate experimental sessions).

\section{EXPERIMENT 2}

\section{Method}

Subjects. Ten students from our laboratory participated in Experiment 2 . All subjects were highly practiced in eye movement experiments but none of the subjects had participated in Experiment 1 .

Apparatus, Procedure, and Materials. The apparatus, procedure, and materials were all the same as in Experiment 1.

Design. Presentation of the two delay conditions for saccade triggering was in separate blocks counterbalanced for training and order effects by a Latin square. Because a previous experiment showed that presenting the two delay conditions within the same experimen- 


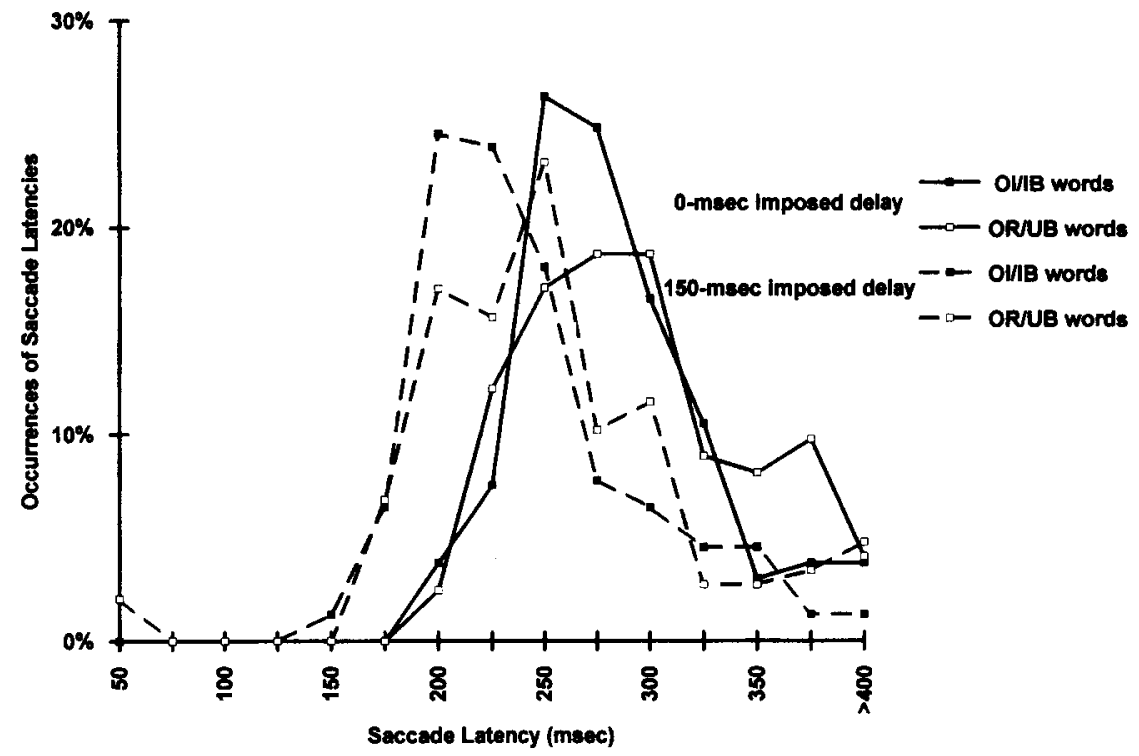

Figure 2. Saccade latency distributions in Experiment 1 as a function of word types and imposed delays. OI/IB, orthographically irregular/informative beginning: OR/UB, orthographically regular/uninformative beginning.

tal session affected the observed saccade latencies, the two delay conditions were presented in two blocks separated by 1 month. Additionally, in order to increase the number of observations in each delay condition, all the words were read in each delay condition. The experimental blocks were preceded by 60 practice trials in both the experimental sessions.

Data analysis. Trials were eliminated in which blinks occurred $(2.7 \%)$, when the eye position measurement was not precise enough $(5.6 \%)$, when anticipatory saccades smaller than $50 \mathrm{msec}(4.6 \%)$ occurred, or when a saccade was initiated before the presentation of the signal to move the eye ( $3 \%)$.

\section{Results}

Landing positions. The mean landing positions (Table 2) replicated the effect of the delay in saccade triggering observed in Experiment 1. Globally, the eye landed farther into the word for the 150- than for the 0 -msec delay condition $\left[F_{1}(1,8)=11.71, p<.01 ; F_{2}(1,70)=70.21\right.$, $p<.0005]$. There was no significant effect of word type $\left(F_{1}\right.$ and $\left.F_{2}<1\right)$. As in Experiment 1, a significant interaction between the imposed delay and the type of word was observed $\left[F_{1}(1,8)=72.26, p<.0005 ; F_{2}(1,70)=\right.$ $21.58, p<.0005]$, indicating that increasing the delay in saccade triggering has a clear effect only on OI/IB words.

Table 2

Mean Landing Positions and Saccade Latencies (in Milliseconds) as a Function of Imposed Delay and Type of Word in Experiment 2

\begin{tabular}{lccccc}
\hline & \multicolumn{4}{c}{ Imposed Delay } \\
\cline { 2 - 3 } \cline { 5 - 6 } Type of & \multicolumn{2}{c}{$0 \mathrm{msec}$} & & \multicolumn{2}{c}{$150 \mathrm{msec}$} \\
\cline { 2 - 3 } \cline { 5 - 6 } Word & Landing & Saccade & & Landing & Saccade \\
\hline OI/IB & 3.24 & 187 & & 3.78 & 203 \\
OR/UB & 3.45 & 190 & & 3.63 & 205 \\
\hline
\end{tabular}

Note-OI/IB, orthographically irregular/informative beginning; OR/UB, orthographically regular/uninformative beginning.
First fixation position was farther into OI/IB words for the 150- than for the 0 -msec delay in saccade triggering $\left[F_{1}(1,8)=20.83, p<.005 ; F_{2}(1,35)=76.69, p<.0005\right]$. Only a weak (marginally significant) effect of delay condition was found for mean landing positions in OR/UB words $\left[F_{1}(1,8)=3.61, p<.10 ; F_{2}(1,35)=7.80, p<\right.$ $.01]$. An examination of the distributions for the different types of words (Figure 3) showed that for OR/UB words, the distributions for the two delay conditions overlapped while they were kept apart about 0.5 character spaces for OI/IB words. Moreover, the data again showed different effects of word type as a function of delay condition. The eye landed closer to the word beginning for OI/IB words than for OR/UB words $\left[F_{1}(1,8)=\right.$ $\left.12.86, p<.01 ; F_{2}(1,70)=8.71, p<.005\right]$ in the absence of imposed delay, but the eye landed farther into OI/IB words than into OR/UB words $\left[F_{1}(1,8)=6.83, p<.05\right.$; $\left.F_{2}(1,70)=8.72, p<.005\right]$ when the saccade triggering was delayed by $150 \mathrm{msec}$.

Saccade latencies. The pattern of data concerning the saccade latencies differed from that observed in Experiment 1 . It can be seen in Table 2 that mean saccade latencies were not longer than usual and, mainly, did not differ as a function of the delay condition $\left[F_{1}(1,8)=1.08\right.$; $\left.F_{2}(1,70)=3.58, p<.10\right]$. Unlike in Experiment 1 , the method of manipulating delay was successful in Experiment 2 . Thus the expected large range of cumulative latencies was obtained. The fact that for each delay condition the observed latency was independent of target position allows us to consider that any effect observed on landing position is not caused by latency effects. Mean latencies did not differ as a function of the type of word $\left(F_{1}\right.$ and $\left.F_{2}<1\right)$. Figure 4 shows that saccade latency distributions for all the conditions were very similar and centered on the same modal value $(200 \mathrm{msec})$. 

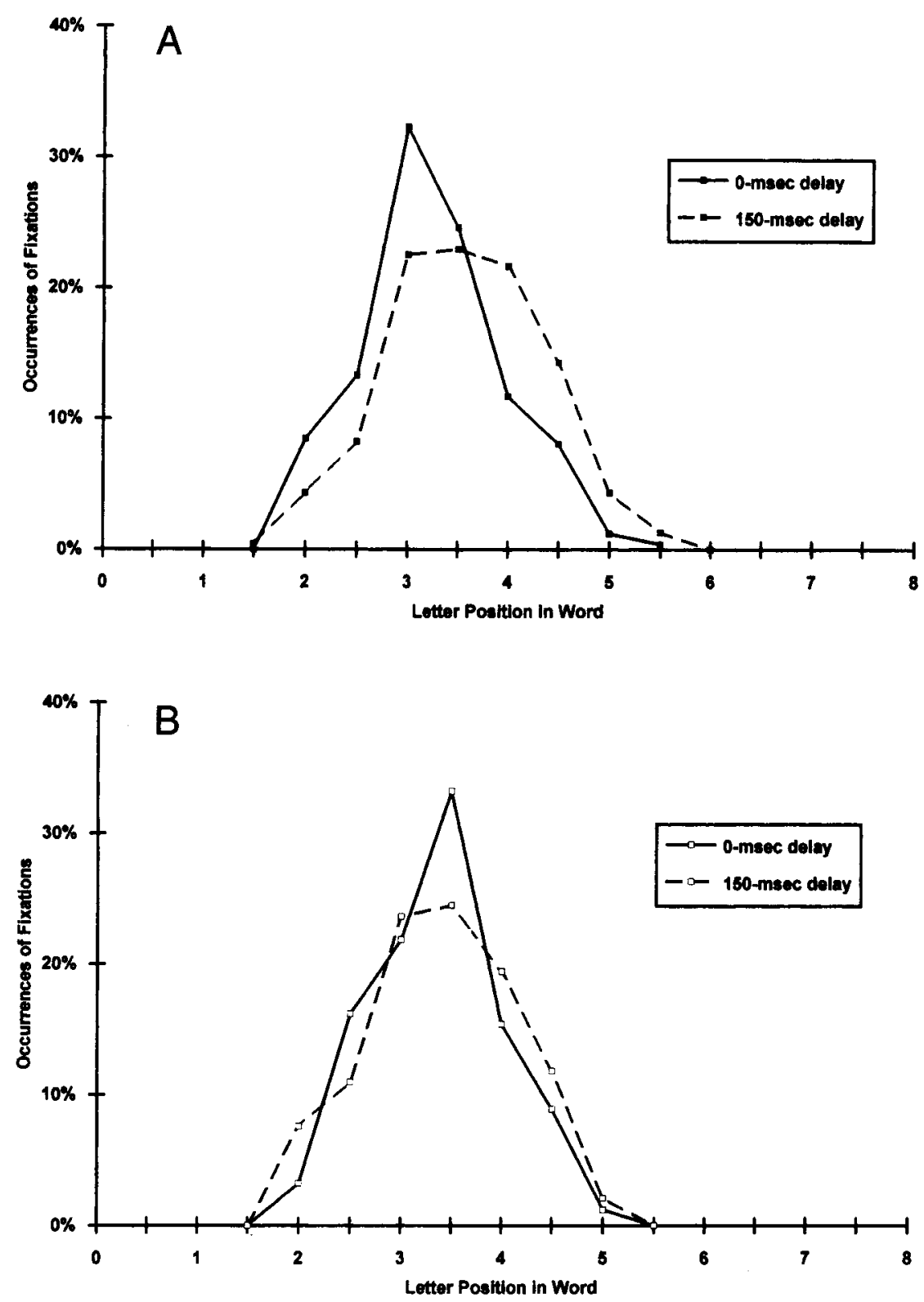

Figure 3. Landing position distributions of primary saccades in Experiment 2 as a function of the two imposed delays for (A) orthographically irregular/informative beginning words and (B) orthographically regular/uninformative beginning words.

Correlation diagrams. The present results show that on average, increasing latency causes landing positions to be farther into the words, mainly for OI/IB words. The fact that the observed latencies were a constant $200 \mathrm{msec}$ longer than the imposed delay in saccade triggering allows us to examine the relationship between saccade latencies and landing positions over a large range of latencies. A regression analysis was performed on landing position against cumulative saccade latency that added the imposed delay to the observed latency separately for OI/IB and $\mathrm{OR} / \mathrm{UB}$ words.

Figure 5 gives correlation diagrams of landing position against cumulative latency. Data from both delays in sac- cade triggering and all subjects have been cumulated in each diagram. Figure $5 \mathrm{~A}$ shows a significant positive correlation $(r=.32)$ between cumulative latency and landing position. For OI/IB words, increasing latency had the effect of causing landing position to be farther into the words. Figure 5B shows where the weakest effect of latency is expected. It is clear in this figure that landing position shows a much less pronounced dependence on latency. Increasing latency in the case of OR/UB words did not clearly modify landing position. Does this mean that the slope of the regression function significantly differed for the two types of word? A regression analysis was performed for each subject of landing posi- 


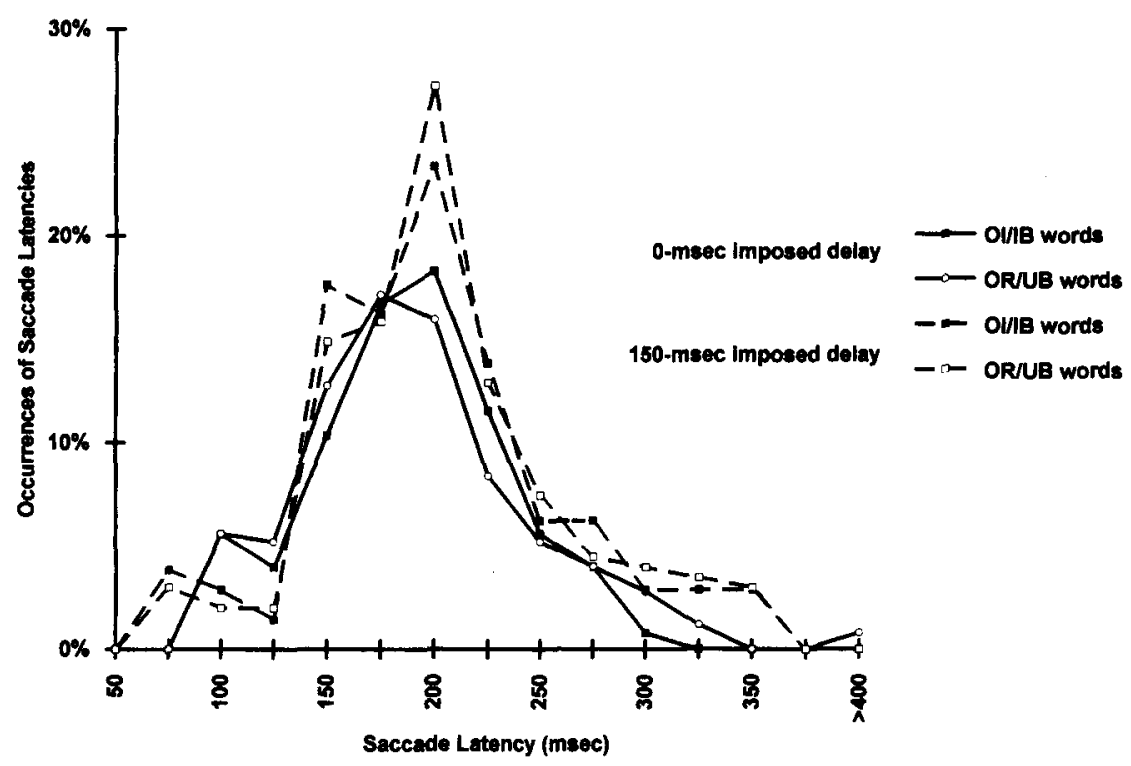

Figure 4. Saccade latency distributions in Experiment 2 as a function of word types and imposed delays. OI/IB, orthographically irregular/informative beginning; OR/UB, orthographically regular/uninformative beginning.

tion against cumulative saccade latency separately for the two types of words. This analysis showed that the slopes of the regression functions were significantly stronger for OI/IB words than for OR/UB words $\left[F_{1}(1,8)=25.8\right.$, $p<.001]$. However, it has to be noted that a significant correlation between landing position and saccade latency for OI/IB words appeared only when a large range of saccade latencies was considered. No correlation was obtained between the two saccade parameters within the ranges of observed saccade latencies for each delay condition. This phenomenon becomes more understandable if it is hypothesized that the critical information integrated by the saccadic system from orthographically irregular and informative word-initial letters differs only if a large range of latencies is considered. At latencies shorter than $250 \mathrm{msec}$, orthographically irregular letters at the word beginning lead to a deviation of landing position toward the word beginning. Informative letters at the word beginning have the effect of increasing the saccade size mainly for latencies longer than $250 \mathrm{msec}$.

\section{GENERAL DISCUSSION}

In the present paper, we have reported results establishing that the effect of the imposed delay in saccade triggering on landing positions in words is a function of the word-initial letters. The results of Experiment 1 suggested that without any delay in saccade triggering, orthographic irregular and informative word-initial letters lead to a deviation of landing positions toward the word beginning. When the saccade was delayed by $150 \mathrm{msec}$, a different effect was found, as landing positions were farther into OI/IB words than into OR/UB words. Experiment 2 replicated the results observed in Experiment 1 under con- ditions in which temporal uncertainty for the moment of saccade triggering was eliminated. Experiment 2 revealed that the relationship between landing position and saccade latency is a function of the properties of the wordinitial letters. Increasing saccade latency only had the effect of increasing saccade size to words that began with orthographically irregular and informative letters. The present experiments have made it possible to reconstruct the relation between the metrics and the latency of saccades over the 200-350-msec range of fixation duration observed in reading. Thus, it appears that the attraction of the eye toward the orthographically irregular bigrams described in earlier studies (Beauvillain et al., 1996) operates by saccadic responses that belong to the normal latency range. Delaying the saccade allows the eyes to avoid this attraction toward the orthographically irregular word-initial letters and to be influenced by a higher level of letter and word integration. An interesting issue to which we now turn is what mechanisms may explain the different metrics-latency relationship in the reading of OI/IB and OR/UB words.

The earlier studies of Findlay (1981a), Viviani and Swensson (1982), Ottes, Van Gisbergen, and Eggermont (1985), and Coëffé and O'Regan (1987) revealed parts of the relationship between saccade metrics and latency in the target-nontarget tracking task. These data show that saccade accuracy increases with time. By using a letter target embedded in a string of nontarget letters, Coëffé \& O'Regan showed that the influence of nontarget letters is attenuated when the moment of saccade triggering is delayed. Ottes et al. proposed that the metrics of visually guided saccades are controlled by a dual subsystem: (1) a short-latency subsystem that is unable to use discrimination information, which automatically 
A

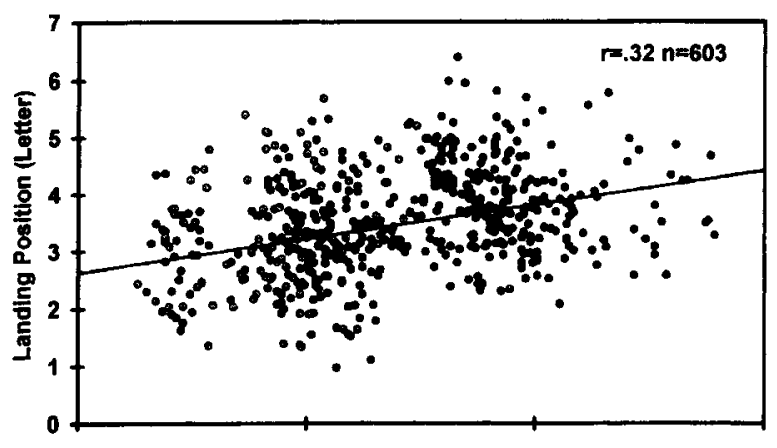

B

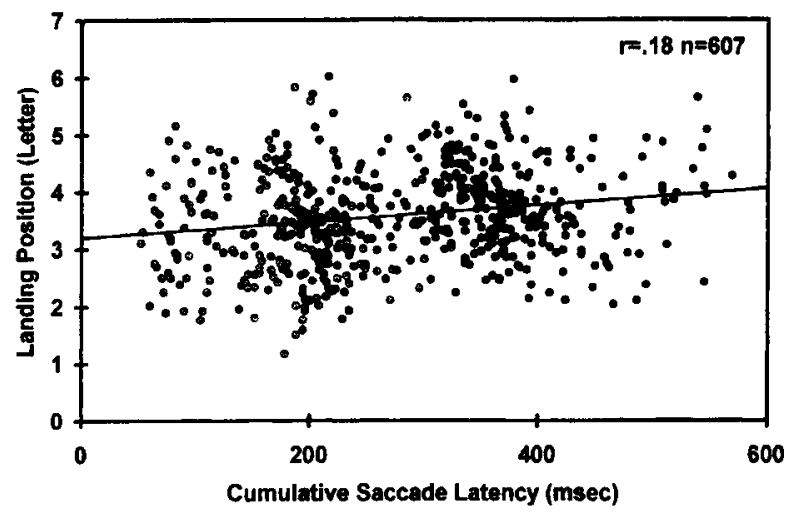

Figure 5. Diagrams of correlation between landing position and cumulative saccade latencies for (A) orthographically irregular/informative beginning words and (B) orthographically regular/uninformative beginning words. The light circles represent the 0 -msec delay data points and the dark circles represent the 150-msec delay data points.

makes a selection based on the global properties of the different stimuli; and (2) a long-latency subsystem with good spatial resolution and feature-extracting capabilities that can be used for the target selection.

In the case of saccades to a word to be identified, no precise target is given to the reader within the word, and the calculation of the saccade endpoint may be influenced by the different processes involved in the identification of letters and words. We may consider that the saccade endpoint changes in time as the letter and word identification process proceeds. The present experiments show that the shorter latency saccades are influenced by the orthographic properties of the word-initial letters. When the orthographic encoding process detects unusual letter groupings at the word beginning, there is a salient signal for the saccade and the eye is attracted by this letter sequence. This refers to preattentive vision that acts automatically and discriminates differences. This does not mean that an unusual letter cluster is the precise target for the reader within the word. The slight but systematic deviation of the landing position distribution observed in the present study and in previous work (Beauvillain et al., 1996) suggests that the center of gravity is calculated mainly on the basis of word length information, with greater weight given to an irregular than a regular letter cluster at the word beginning. ${ }^{1}$ In addition, the present experiments show that the orthographic encoding of the word-initial letters is integrated during the normal oculomotor RTs of about $200 \mathrm{msec}$. This is also consistent with the fact that in a text-reading situation, saccade length has been shown to be shortened when the parafoveal letter string was orthographically inappropriate (McConkie, Underwood, Zola, \& Wolverton, 1985). Interestingly, it was shown in that study that orthographically inappropriate information has to be presented early in the prior fixation in order to influence the saccade size.

Under normal circumstances, saccades are generally triggered before other sources of linguistic information are consulted. With time, the word identification process proceeds and the saccade endpoint may be influenced by lexical information derived from the initial letters of the parafoveal word. With greater identification of the first part of the word, a lexical representation may be more easily contacted when the informative value of the word initial letters is unambiguous. Thus, when the word-initial letters determine only one lexical candidate, as it is the case of the OI/IB words, a lexical representation can be more easily activated in parafovea from the word-initial letters. This does not imply that the word has been completely identified before the saccade has been initiated. Identification of the word-initial letters may yield sufficient activation of one lexical unit to affect saccade size before the word recognition threshold has been reached. Thus, the lexical access may have reached a certain degree of activation and the eye lands farther into the word. When the informative value of the word initial letters is ambiguous, as in the case of OR/UB words, for which the size of the set of potential word candidates sharing the initial letters is important, identification of the word-initial letters may not allow activation of one lexical unit.

If the observed effect on landing position in the 150msec condition was primarily due to the lexical information activated in parafovea from the word's beginning letters, this should have facilitated the subsequent acquisition of the word information. Such a mechanism predicts that the benefit from word-initial letters should be greater when their informational value is unambiguous. This should be reflected in shorter reading times on OI/IB words than on OR/UB words. To assess the possibility that our landing position effects reflect differences in the parafoveal processing of the two types of word, we analyzed the data of the participants included in the second experiment to determine whether such an explanation is plausible.

In fact, as shown in Table 3, the benefit from the parafoveal processing in the $150-\mathrm{msec}$ condition was greater for OI/IB words than for OR/UB words, as reflected by the significant interaction observed for gaze durations between delay in saccade triggering and type of words $\left[F_{1}(1,8)=12.95, p<.01\right]$. Moreover, it can be seen from Table 3 that the effect in gaze duration was not due 
Table 3

Mean Probability of Refixations (Percentage), Gaze Durations, and Single-Fixation Durations (in Milliseconds) on the Target Word as a Function of Imposed Delays and Type of Word in Experiment 2

\begin{tabular}{lccccccc}
\hline & \multicolumn{9}{c}{ OI/1B } & & & \multicolumn{2}{c}{ OR/UB } \\
\cline { 2 - 4 } \cline { 7 - 8 } Delay & $\begin{array}{c}\text { Probability of } \\
\text { Refixation }\end{array}$ & $\begin{array}{c}\text { Gaze } \\
\text { Duration }\end{array}$ & $\begin{array}{c}\text { Single-Fixation } \\
\text { Duration }\end{array}$ & $\begin{array}{c}\text { Probability of } \\
\text { Refixation }\end{array}$ & $\begin{array}{c}\text { Gaze } \\
\text { Duration }\end{array}$ & $\begin{array}{c}\text { Single-Fixation } \\
\text { Duration }\end{array}$ \\
\hline $0 \mathrm{msec}$ & .33 & 270 & 232 & & .35 & 268 & 234 \\
$150 \mathrm{msec}$ & .12 & 223 & 214 & & .20 & 248 & 231 \\
Difference & $.21 \dagger$ & $477_{\ddagger}^{+}$ & $18^{*}$ & & $.15^{*}$ & $20 \S$ & $3 \S$ \\
\hline
\end{tabular}

Note-OI, orthographically irregular; IB, informative beginning; UB, uninformative beginning. Gaze duration represents the sum of fixations on the target word. ${ }^{*} p<.05 . \quad{ }^{t} p<.01 . \quad{ }^{\ddagger} p<.005 . \S \mathrm{n} . \mathrm{s}$.

only to the probability that the word was fixated twice, since the pattern of single-fixation duration corresponded quite closely to the pattern of gaze duration. Delaying the saccade triggering to a target word also shortened the fixation duration when the word was read with one fixation. Clearly, the recognition time of the word is reduced to a greater degree when the parafoveal processing of the initial letters has allowed the activation of one lexical unit. Thus, our manipulation of delaying the saccade triggering for OI/IB words had an effect on the saccade programming as well as on the recognition of the word. Obtaining lexical information from a parafoveally available word serves two purposes: It is used to determine the positioning of the eyes within the word, and it facilitates the recognition of the word during the next fixation. This type of functional relation between the programming of the saccade to words and the subsequent acquisition of word information argues for an effect of some importance in the understanding of eye movement control in reading. At short latencies, the parafoveal information that affects saccade programming is not lexically mediated but only related to the detection of an infrequent letter sequence. At long latencies, with word-extraction capabilities the saccadic system may use lexical information derived from the word-initial letters mainly if their informative value is unambiguous.

There remain, however, a number of important issues that must be considered in a fuller account of the relation between the amplitude of the saccade to a target word and the lexical information extracted from that word. This increasing of the saccade size may be presumed to arise because the execution of the saccade to the target word is modified by the preparation of the second saccade. As the processing of the parafoveal word is more elaborated, the influence of the second saccade to peripheral targets becomes stronger. This would explain a deviation of landing positions in the direction of the second saccade. This increasing of saccade size can be explained by a parallel programming hypothesis (Becker \& Jürgens, 1979), according to which the saccadic system can work at the preparation of two different saccadic responses simultaneously. The two saccades may compete for processing at various stages, resulting in complex interactions and partial or complete redirection of the first saccade. Such a notion has been proposed for in-text reading (Morrison, 1984; see also Henderson \& Ferreira, 1990). If computations begin on the movement for word $n+2$ before the initiation of the saccade toward word $n+1$, the two saccadic programs may interfere with each other. Thus, occasionally, word $n+1$ can be skipped. In other cases, the eye fixation location should be shifted toward the end of word $n+1$. Our results show that the computation of the subsequent saccade modifies the saccade toward a parafoveal word only when its beginning is informative. The present findings suggest that the computation of the subsequent saccade has an influence on the saccade toward a target word mainly when the processing of this word is sufficiently elaborated before the triggering of the saccade to it.

\section{REFERENCES}

Balota, D. A., Pollatsek, A., \& Rayner, K. (1985). The interaction of contextual constraints and parafoveal visual information in reading. Cognitive Psychology, 17, 364-390.

Beauvillain, C., \& Beauvillain, P. (1995). Calibration of an eyemovement system for use in reading. Behavior Research Methods, Instruments, \& Computers, 27, 331-337.

Beauvillain, C., Doré, K., \& Baudouin, V. (1996). The "center of gravity" of words: Evidence for an effect of the word-initial letters. Vision Research, 36, 589-603.

BECKER, W., \& JÜRGENS, R. (1979). An analysis of the saccadic system by means of double step stimuli. Vision Research, 19, 967-983.

COËFFÉ, C., \& O'REGAN, J. K. (1987). Reducing the influence of nontarget stimuli on saccade accuracy: Predictability and latency effects. Vision Research, 27, 227-240.

Cohen, M. E., \& Ross, L. E. (1977). Saccade latency in children and adults: Effects of warning interval and target eccentricity. Journal of Experimental Child Psychology, 23, 539-549.

CoHEN, M. E., \& Ross, L. E. (1978). Latency and accuracy characteristics of saccades and corrective saccades in children and adults. Journal of Experimental Child Psychology, 26, 517-527.

Deubel, H., Wolf, W., \& Hauske, G. (1984). The evaluation of the oculomotor error signal. In A. G. Gale \& F. Johnson (Eds.), Proceedings of the Second European Conference on Eye Movements: Theoretical and Applied Aspects of Eye Movement Research (pp. 5562). Amsterdam: Elsevier.

FindLAY, J. M. (1981a). Local and global influences on saccadic eye movements. In D. F. Fisher, R. A. Monty, \& J. W. Sanders (Eds.), Eye movements: Cognition and visual perception (pp. 171-177). Hillsdale, NJ: Erlbaum.

FINDLAY, J. M. (1981b). Spatial and temporal factors in the predictive generation of saccadic eye movements. Vision Research, 21, 347-354.

FINDLAY, J. M. ( 1982). Global visual processing for saccadic eye movements. Vision Research, 22, 1033-1045. 
Henderson, J. M., \& Ferreira, F. (1990). Effect of foveal processing difficulty on the perceptual span in reading: Implications for attention and eye movement control. Journal of Experimental Psychology: Learning, Memory, \& Cognition, 16, 417-429.

Hogaboam, T. W. (1983). Reading patterns in eye movement data. In $\mathrm{K}$. Rayner (Ed.), Eye movements in reading: Perceptual and language processes (pp. 309-332). New York: Academic Press.

HYÖNÄ, J. (1995). Do irregular letter combinations attract readers' attention? Evidence from fixation locations in words. Journal of Experimental Psychology: Human Perception \& Performance, 21, 6881.

INHOFF, A. W. (1989). Parafoveal processing of words and saccade computation during eye fixations in reading. Journal of Experimental Psychology: Human Perception \& Performance, 15, 544-555.

InHOFf, A. W., \& RaYNeR, K. (1986). Parafoveal word processing during eye fixations in reading: Effects of word frequency. Perception \& Psychophysics, 40, 431-439.

McConkie, G. W., KerR, P. W., Reddix, M. D., \& Zola, D. (1988). Eye movement control during reading: The location of initial eye fixations on words. Vision Research, 27, 227-240.

McConkie, G. W., Underwood, N. R., Zola, D., \& Wolverton, G. S. (1985). Some temporal characteristics of processing during reading. Journal of Experimental Psychology: Human Perception \& Performance, 11, 168-186.

Michard, A., TÊTARD, C., \& LÉvy-SChoen, A. (1974). Attente du signal et temps de réaction oculomoteur [Waiting for signal and oculomotor reaction time]. L'Année Psychologique, 74, 387-402.

Morris, R. K., Rayner, K., \& Pollatsek, A. (1990). Eye movement guidance in reading: The role of parafoveal letter and space information. Journal of Experimental Psychology: Human Perception \& Performance, 16, 268-281.

MORRISON, R. E. (1984). Manipulation of stimulus onset delay in reading: Evidence for parallel programming of saccades. Journal of Experimental Psychology: Human Perception \& Performance, 10, 667-682.

O'REGAN, [J.] K. (1979). Saccade size control in reading: Evidence for the linguistic control hypothesis. Perception \& Psychophysics, 25, $501-509$

Ottes, F. P., Van Gisbergen, J. A., \& Eggermont, J. J. (1985). Latency dependence of colour-based target vs nontarget discrimination by the saccadic system. Vision Research, 25, 849-862.

Pollatsek, A., \& Rayner, K. (1982). Eye movement control in reading: The role of word boundaries. Journal of Experimental Psychology: Human Perception \& Performance, 8, 817-833.

Pollatsek, A., Rayner, K., \& Balota, D. A. (1986). Inferences about eye movement control from the perceptual span in reading. Perception \& Psychophysics, 40, 123-130.

RAYNER, K. (1979). Eye guidance in reading: Fixation location within words. Perception, 8, 21-30.

Rayner, K., MCConkie, G. W., \& Zola, D. (1980). Integrating information across eye movements. Cognitive Psychology, 12, 206-226.

Rayner, K., Slowiaczek, M. L., Clifton, C., \& Bertera, J. H. (1983). Latency of sequential eye movements: Implications for reading. Journal of Experimental Psychology: Human Perception \& Performance, 9, 912-922.

Rayner, K., Well, A. D., Pollatsek, A., \& Bertera, J. H. (1982). The availability of useful information to the right of fixation in reading. Perception \& Psychophysics, 31, 537-550.

Ross, L. E., \& Ross, S. M. (1980). Saccade latency and warning signals: Stimulus onset, offset, and change as warning events. Perception \& Psychophysics, 27, 251-257.

Ross, S. M., \& Ross, L. E. (1981). Saccade latency and warning signals: Effects of auditory and visual stimulus onset and offset. Perception \& Psychophysics, 29, 429-437.

TRESOR DE LA LANGUE FRANÇAISE (1971). Dictionnaire des fréquences. Paris: Klincksieck.

VITU, F. (1991). The existence of a center of gravity effect during reading. Vision Research, 31, 1289-1313.

VIVIANI, P., \& SWENSSON, R. G. (1982). Saccadic eye movements to peripherally discriminated visual targets. Journal of Experimental Psychology: Human Perception \& Performance, 8, 113-126.

\section{NOTE}

1. The failure to find a systematic deviation of the whole landing position distribution toward the word beginning led Hyönä (1995) to propose another plausible account of the orthographic effect. Indeed, the data presented by this author showed a secondary peak in the landing position distribution in the space preceding a target word that began with an orthographically irregular letter cluster. Hyönä suggested that in the presence of an irregular letter cluster, the saccade target is not the word's center but rather the space preceding the word that is another easily identifiable feature. This modification of the saccade target should be caused by the momentary processing difficulty in the orthographic encoding of an unusual letter cluster at the word's beginning that modifies the saccade target. However, it is unclear whether or not this secondary peak in the landing position distribution obtained in Hyönä's study is due to different launching sites. The present data showed that, when the launching site and the eccentricity of the parafoveal word are held constant, the orthographic effect results in a slight but systematic deviation of the whole landing position distribution.

\section{APPENDIX}

Stimulus Pairs for Experiments 1 and 2

\begin{tabular}{cc}
\hline $\begin{array}{c}\text { Orthographically } \\
\text { Irregular/Informative } \\
\text { Beginning Words }\end{array}$ & $\begin{array}{c}\text { Orthographically } \\
\text { Regular/Uninformative } \\
\text { Beginning Words }\end{array}$ \\
\hline lyncher & courser \\
glycine & mouture \\
gabarit & macaron \\
layette & roulade \\
siamois & potiron \\
hypnose & passade \\
léopard & compote \\
lexique & calorie \\
cajoler & parader \\
oseille & termite \\
miauler & percher \\
jubiler & cracher \\
tzigane & montage \\
vampire & cuisson \\
segment & carence \\
cymbale & poussin \\
méandre & potence \\
hirsute & poterie \\
édredon & entrave \\
luzerne & carrure \\
vedette & boutade \\
nuptial & conteur \\
spirale & bouchon \\
kiosque & portion \\
fébrile & couture \\
ajuster & colorer \\
éblouir & courber \\
lugubre & coussin \\
syllabe & collier \\
moyenne & contrat \\
rupture & paresse \\
taureau & partage \\
inquiet & couteau \\
bizarre & couloir \\
janvier & terrain \\
juillet & fortune \\
\hline & \\
\hline &
\end{tabular}

(Manuscript received September 18, 1995; revision accepted for publication June $5,1996$. 